\section{Discography for Preoperative Evaluation of Patients with Chronic Low Back Pain and Its Effect on Clinical Results}

\section{Abstract}

Background context: Degeneration of intervertebral discs can sometimes cause chronic pain known as degenerative disc disease (DDD), and this condition is primarily treated conservatively. If this fails, surgery can be considered; these patients are often assessed through medical history, clinical findings, and radiology. In some patients uncertainty prevails, therefore additional examinations might be beneficial. One such examination is provocative discography, but its reliability is disputed. No studies have been performed on the impact of discography on clinical outcome after surgery.

Purpose: To determine whether information obtained from discography might affect the clinical outcome of surgical interventions in patients with suspected DDD.

Study design: A retrospective outcome study with data 1 and 2 years after surgery for DDD.

Patient sample: The patient sample consisted of 99 patients with DDD primarily judged as uncertain or complicated, divided into four subgroups according to the reason for clinical uncertainty, and subsequently examined with discography.

Outcome measures: The data were reported using a self-assessment questionnaire with validated outcome variables of pain, function, and quality of life.

Methods: To evaluate the results after surgery, the outcome of the uncertain patient groups who underwent discography was compared with a control group of 988 patients who were not examined with discography.

Results: The discography group had significantly worse results compared with the control group in 10 of the 12 variables analyzed. However, the results after surgery for two of the four subgroups were similar to the results for the control group. Despite this extended preoperative examination, the patients in the remaining two subgroups had a poorer outcome.

Conclusion: Discography may in highly selected cases have a positive effect on outcome in some patients with suspected complicated chronic low back pain due to DDD. Results differ depending on the reason for discography and further research on this is needed.

Keywords: Chronic low back pain; Degenerative disc disease; Discography; Intervertebral disc degeneration; Treatment outcome

\section{Wilhelm Gillnäs and Svante Berg \\ Stockholm Spine Center Upplands Väsby, Sweden}

\section{Corresponding author: Svante Berg}

झ svante.berg@spinecenter.se

Stockholm Spine Center, Löwenströmska Hospital, Upplands Väsby 194 89, Sweden.

Tel: +46850902700

Citation: Gillnäs W, Berg S. Discography for Preoperative Evaluation of Patients with Chronic Low Back Pain and Its Effect on Clinical Results. Neurosurg. 2016, 1:3. 


\section{Introduction}

A large part of a community's resources dedicated to health care and sick leave is taken up by chronic low back pain (CLBP). Back disorders negatively affect the individual, leading to pain, suffering, decreased quality of life, and disability. Pain emanating from degenerative changes in the motion segment between the lumbar vertebrae is the most frequent cause of sick leave among people with CLBP [1-3].

CLBP with or without radicular pain but without neurogenic claudication can be caused by degenerative disc disease (DDD), which was first proposed by Crock in 1970 [4]. Patients with CLBP because of DDD should always try conservative treatment before surgery is considered [5]. It is well documented that conservative treatment may reduce pain, improve the ability to cope with the residual pain, and restore working capacity $[5,6]$. When conservative treatment is unsuccessful, surgery can be considered [6-8]. Patients with CLBP due to DDD are usually minimally symptomatic in certain body positions, but often experience increased low back pain in other positions, movements, and loads. Patients evaluated for surgery are judged on medical history including symptoms, clinical examination, and radiologic examinations such as magnetic resonance imaging (MRI). Further understanding of which anatomic structures are responsible for the pain is often warranted.

When CLBP is suspected to be caused by DDD, one option to gain further information is to perform discography $[9,10]$. However, discography is a controversial diagnostic method. Although criteria for a positive discogram have been adopted since 1994 [11], an accurate reference standard (or criterion standard) for evaluation of diagnostic accuracy is lacking [12-14]. Sensitivity is extremely difficult to assess. In a study by Wolfer et al. [10], the false-positive rate was estimated to be low, provided standardized techniques were used and criteria were met. In that study, discography of non-degenerated discs was used as a reference standard. Although it is possible that discography might be particular helpful in making decisions for certain subgroups of patients, discography was often used routinely before a decision was made on surgical treatment for painful DDD. Since the negative effects of discography for non-degenerated discs have been presented, the use seems to be more restricted [15].

A recent study [16] revealed the risk of increased pressure in adjacent discs when one suspected disc is injected/pressurized, making the provocation face more uncertain. When using the technique with provocation of pain due to pressure followed by an attempt to reduce pain with local anesthetic, the possible effect of these findings seems to be reduced. When searching the literature, data on subgroups and reports on what clinical questions might be answered by discography are scarce [14]. Clearly, it is important to determine when diagnostic tests are appropriate or useful. Referral guidelines for imaging [17] define a useful investigation as one in which the result, positive or negative, will alter clinical management and/or add confidence to the clinician's diagnosis.

Fryback and Thornbury presented a system of levels at which effectiveness of diagnostic imaging might be determined. Technical efficacy and diagnostic accuracy are labeled level 1 and level 2, respectively; level 3 and level 4 (diagnostic thinking efficacy and therapeutic efficacy) define the usefulness of an examination in accordance with guidelines mentioned previously. Level 5 is defined as the ability of a diagnostic test to influence the short-term or long-term health outcome. Studies on level 3 or level 4 might be based on a so-called before-after prospective design [18].

Using Fryback's system of levels as a starting point, our previously published study used a prospective before-after design to compare the value of discography in relation to different clinical considerations in patients who were clinically difficult to evaluate [19]. Patients in the study group were divided into four subgroups based on the type of uncertainty, that is, what was the reason for the discography. An overall change rate of $71 \%$ including both treatment and segment changes, from pre-discography decisions to post-discography re-decisions was noted. The pattern of changes was different for the four subgroups.

The actual outcome after surgical treatment for this difficult group of patients, and for the respective subgroups, is examined. Is there reason to believe that outcome was improved by the effect discography had on the actual treatment? This retrospective outcome study based on register data on the same patient group is an attempt to provide some answers. The data are based on voluntary participation and registration has been ongoing since the mid-1990s [20]. Patients are informed that data from the registry are used for scientific studies and quality control. The registry has been approved by the Swedish Personal Data Act (PUL) and has been validated for the storage and processing of treatment data. The study was entirely financed with department funds.

\section{Methods}

\section{The patient sample}

Because of the risk of complications as a result of the discography procedure, we restrict its use to uncertain cases only, which consists of approximately $15 \%$ of all patients treated for CLBP due to DDD in our clinic during the time of this study [21]. In this study, the focus is on comparing the clinical outcome between the discography groups, including the individual subgroups, with a control group. The patients in the control group also had a diagnosis CLBP due to DDD, but their surgery was not preceded by discography. Surgery in both groups took place during the same time period at the same clinic. For a description of how discography was performed and judged, see the previous article from this study. All patients in the outcome study were treated with fusion or total disc replacement and their baseline data and clinical results were self-reported by completed questionnaires from SweSpine [20]. Attending surgeons were orthopedic- or neurosurgeons with a long experience of this type of surgery.

Of the 138 patients who completed the previous discography study [18], 99 patients who actually underwent surgery after discography were included in this study. The patients were divided into four subgroups based on the reason for the discography: 
1. Surgery decided, discography to establish whether to treat adjacent segments as well;

2. Several segments degenerated on MRI; pain likely to be discogenic, discography to evaluate what segments to treat;

3. Uncertainty whether pain is discogenic but one suspected segment on $\mathrm{MRI}$;

4. Uncertainty whether pain is discogenic and several segments degenerated on MRI.

There were 13 patients in subgroup 1, 44 patients in subgroup 2, 22 patients in subgroup 3, and 20 patients in subgroup 4 . Of the 39 patients who were not included in the present study, the decision after discography in 28 of those patients was not to perform surgery. Five patients did not have Swedish social security numbers and thus were not followed through SweSpine. Five patients were scheduled for surgery but surgery never took place for different reasons. One patient died of an unrelated cause some time after discography and a surgical decision but before treatment was performed (Figure 1).

The control group is considered to be a less complicated and uncertain patient group; the attending surgeon did not feel the need for discography to determine which spinal segment(s) to propose for surgery. This group consisted of 988 patients who were all treated at the same clinic and for the same diagnosis (DDD) as the discography group.

\section{Outcome analysis}

The outcome analysis was performed from data collected in the SweSpine questionnaires including Global Assessment (GA) of back pain [22], European Quality of Life 5D (EQ5D) [23], Oswestry Disability Index (ODI) [24], Short Form Health Questionnaire (SF36) [25], and a Visual Analog Scale (VAS) for back pain reported after 1 and 2 years. These outcome measures are frequently used for evaluation of surgery for CLBP [26].

Methodologically, the two groups are not exactly similar, because the patients in the discography group were assessed as being more clinically or radiologically complicated, but all the patients in the two groups were diagnosed and treated surgically for CLBP due to DDD between January 2006 and December 2010.

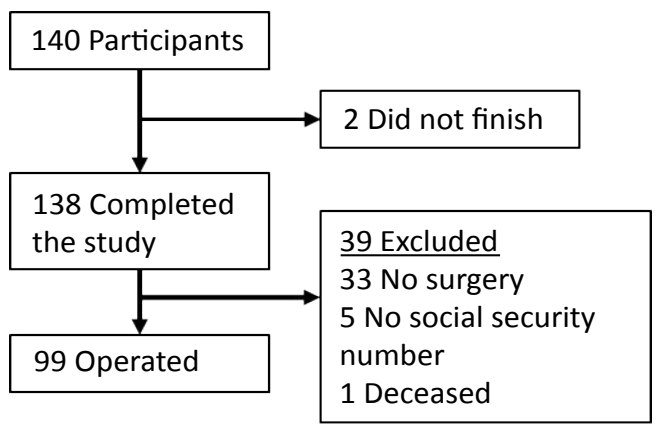

Figure 1 Flowchart showing exclusion of patients from previous discography study.

\section{Statistical analysis}

The baseline frequencies, number of participants, sex distribution, mean and median were calculated for the whole group and the individual groups. GA was calculated with Pearson's $\chi^{2}$ test. Confidence intervals and standard deviations were calculated using the Wilcoxon rank sum test for all parameters. The MannWhitney $U$ test was used to compare parameters throughout the group and calculate $P$ values. Both the Wilcoxon rank sum test and the Mann-Whitney $U$ test make no distributional assumptions and were chosen because of the big difference in size between the groups. A $P$ value $<0.05$ was considered significant. The statistical calculations were performed with IBM SPS 22.

\section{Results}

The study includes 99 patients who underwent surgery after discography, divided into four subgroups according to the indication for discography as reported in the previous study and explained earlier. Comparison with the control group consisting of 988 patients was done for the group as a whole and the four individual subgroups independently. The subgroups were also compared with each other. The sex distribution in the entire cohort (the study group and the control group) was $50.14 \%$ (545) males and $49.86 \%$ (542) females. In the control group, the distribution was $50.3 \%$ (497) males and $49.7 \%$ (491) females. The study group consisted of $48.48 \%$ (48) males and $51.51 \%$ (51) females. The distribution in the individual subgroups is shown in Table 1.

When comparing outcomes for the study group of patients who underwent discography with the control group, we found significant differences for 10 of 12 parameters. The control group had significantly better results in each case. The ten parameters were VAS for back pain at 2 years, EQ5D at both 1 and 2 years, SF36 Mental Score Index (MCS) at 2 years, the Physiological Sum Index (PCS) at both 1 and 2 years, ODI at both 1 and 2 years, and GA for back pain at both 1 and 2 years (Tables 2 and 3 ).

Analysis of subgroup 1 , with the expected least uncertainty, against the control group showed no significant differences in any of the outcome variables. Thus, it was not possible to show a different result after surgery between this subgroup and the control group as shown in Table 4. GA for all subgroup analyses versus the control group is shown in Table 3.

On the other hand, when subgroup 2 was analyzed against the control group, the results were significantly worse for four outcome variables (EQ5D at 2 years, SF36 MCS at 2 years, PCS at 1 year, and GA for back pain at 2 years). The other variables showed no significant differences between the two groups. The variables analyzed are shown in Table 5. GA values are shown in Table 3.

Subgroup 3 was compared with the control group and showed significant differences in 11 variables. The results were worse for the following variables: VAS for back pain at both 1 and 2 years, EQ5D at both 1 and 2 years, SF36 MCS at both 1 and 2 years, PCS at 1 years, ODI at both 1 and 2 years, and GA for back pain at both 1 and 2 years. The variables analyzed are shown in Table 6. GA values are shown in Table $\mathbf{3}$. 
Table 1 Age and gender distribution between the respective subgroups and the control group, given as numbers $(N)$ and percentages.

\begin{tabular}{|c|c|c|c|c|c|c|}
\hline \multirow{2}{*}{ Group } & \multirow{2}{*}{ Gender } & \multicolumn{2}{|c|}{ Discography } & \multicolumn{2}{|c|}{ Total } & \multirow{2}{*}{$\begin{array}{l}\text { Age range, year } \\
\text { (median) }\end{array}$} \\
\hline & & No & Yes & $N$ & $\%$ & \\
\hline \multirow{3}{*}{ Control group } & Male & 497 & & 497 & 50.30 & \\
\hline & Female & 491 & & 491 & 49.70 & \\
\hline & Total & 988 & & 988 & & $18-80(44)$ \\
\hline \multirow{3}{*}{ Subgroup 1} & Male & & 6 & 6 & 46.15 & \\
\hline & Female & & 7 & 7 & 53.85 & \\
\hline & Total & & 13 & 13 & & $20-50(38)$ \\
\hline \multirow{3}{*}{ Subgroup 2} & Male & & 24 & 24 & 54.55 & \\
\hline & Female & & 20 & 20 & 45.45 & \\
\hline & Total & & 44 & 44 & & $22-62(45.5)$ \\
\hline \multirow{3}{*}{ Subgroup 3} & Male & & 7 & 7 & 31.82 & \\
\hline & Female & & 15 & 15 & 68.18 & \\
\hline & Total & & 22 & 22 & & $19-62$ (41.5) \\
\hline \multirow{3}{*}{ Subgroup 4} & Male & & 11 & 11 & 55.00 & \\
\hline & Female & & 9 & 9 & 45.00 & \\
\hline & Total & & 20 & 20 & & $28-57(42)$ \\
\hline \multirow{3}{*}{ Total } & Male & 497 & 48 & 545 & 50.14 & \\
\hline & Female & 491 & 51 & 542 & 49.86 & \\
\hline & Total & 988 & 99 & 1087 & & $18-80(44)$ \\
\hline
\end{tabular}

Table $\mathbf{2}$ The continuous outcome parameters for the entire study group versus the control group.

\begin{tabular}{|c|c|c|c|c|c|c|c|c|c|}
\hline \multirow{2}{*}{ Parameter } & \multicolumn{4}{|c|}{ Control group } & \multicolumn{4}{|c|}{ Discography group } & \multirow{2}{*}{$P$ value } \\
\hline & $N$ & Median & Mean & SD & $N$ & Median & Mean & SD & \\
\hline VAS back pain 1 year & 830 & 18.00 & 27.79 & 26.37 & 83 & 27.00 & 34.99 & 27.92 & 0.119 \\
\hline VAS back pain 2 years & 718 & 17.00 & 27.59 & 27.86 & 84 & 26.00 & 37.11 & 32.14 & 0.003 \\
\hline EQ5D 1 year & 831 & 0.76 & 0.67 & 0.30 & 85 & 0.73 & 0.59 & 0.32 & 0.024 \\
\hline EQ5D 2 years & 723 & 0.80 & 0.68 & 0.32 & 86 & 0.73 & 0.56 & 0.35 & $<0.001$ \\
\hline MCS (SF36) 1 year & 833 & 42.98 & 41.80 & 11.37 & 85 & 37.80 & 39.83 & 11.44 & 0.157 \\
\hline MCS (SF36) 2 years & 723 & 44.94 & 42.68 & 12.21 & 86 & 41.07 & 40.07 & 12.90 & 0.005 \\
\hline PCS (SF36) 1 year & 833 & 52.03 & 47.50 & 12.39 & 85 & 46.09 & 43.15 & 12.80 & 0.012 \\
\hline PCS (SF36) 2 years & 723 & 52.62 & 47.29 & 12.62 & 86 & 49.95 & 43.75 & 14.10 & 0.003 \\
\hline ODI 1 year & 830 & 20.00 & 22.65 & 18.28 & 85 & 26.00 & 28.41 & 18.76 & 0.018 \\
\hline ODI 2 years & 722 & 18.00 & 22.07 & 19.09 & 85 & 26.00 & 27.48 & 20.29 & 0.002 \\
\hline
\end{tabular}

VAS: Visual Analog Scale for pain; EQ5D: European Quality of life 5 Dimensions; SF36: Short Form Health Questionnaire; MCS: Mental Score Index; PCS: Physiological Score Index; ODI: Oswestry Disability Index; N: number of patients; SD: Standard Deviation

Table 3 GA analysis.

\begin{tabular}{|c|c|c|c|}
\hline Discography & GA 1-2 at 1(N)/2 years(N) & GA 3-5 at 1(N)/2 years(N) & P value \\
\hline Yes, total & $54 \%(46) / 50 \%(43)$ & $46 \%(39) / 50 \%(43)$ & $0.0357 / 0.0005$ \\
\hline Subgroup 1 & $78 \%(7) / 70 \%(7)$ & $22 \%(2) / 30 \%(3)$ & $0.4637 / 0.9758$ \\
\hline Subgroup 2 & $58 \%(22) / 50 \%(18)$ & $42 \%(16) / 50 \%(18)$ & $0.3081 / 0.0160$ \\
\hline Subgroup 3 & $32 \%(6) / 29 \%(6)$ & $68 \%(13) / 71 \%(15)$ & $0.0019 / 0.0000$ \\
\hline Subgroup 4 & $58 \%(11) / 63 \%(12)$ & $42 \%(8) / 37 \%(7)$ & $0.4606 / 0.5557$ \\
\hline No, control & $66 \% / 70 \%$ & $34 \% / 30 \%$ & \\
\hline
\end{tabular}

GA score: 1 : totally pain free; 2 : greatly improved; 3 : somewhat better; 4 : unchanged; 5 : worse. Percentage of GA score 1-2 and GA score 3-5 for total discography group and the respective subgroups at 1 and 2 years compared with the control group $P: 2$-sided significance calculated with Pearson's $\chi^{2}$ test

Comparison of subgroup 4, with the expected highest uncertainty, with the control group showed no significant differences for any of the outcome variables. Thus, it was not possible to show a different result after surgery for this group when analyzed against the comparative group. The results for this analysis are shown in Table 7. GA for all subgroup analyses versus the control group is shown in Table 3.

\section{Discussion}

The previously published study on this patient cohort revealed that plans were frequently altered after the results of discography were added to other clinical and radiologic information. As commented by the editor on publication, it remains unclear whether the added information and possible 
Table 4 Subgroup 1 analyzed against the control group.

\begin{tabular}{|c|c|c|c|c|c|c|c|c|c|}
\hline \multirow[t]{2}{*}{ Parameter } & \multirow{2}{*}{$\begin{array}{c}\text { Control group } \\
N\end{array}$} & \multicolumn{7}{|c|}{ Subgroup 1} & \multirow[t]{2}{*}{$P$ value } \\
\hline & & Median & Mean & SD & $N$ & Median & Mean & SD & \\
\hline VAS back pain 1 year & 830 & 18 & 27.79 & 26.37 & 9 & 27 & 30.5 & 29.06 & 0.723 \\
\hline VAS Back pain 2 years & 718 & 17 & 27.59 & 27.86 & 10 & 2 & 27.63 & 38.78 & 0.525 \\
\hline EQ5D 1 year & 831 & 0.76 & 0.67 & 0.3 & 9 & 0.76 & 0.6 & 0.41 & 0.642 \\
\hline EQ5D 2 years & 723 & 0.8 & 0.68 & 0.32 & 10 & 0.79 & 0.6 & 0.48 & 0.721 \\
\hline MCS (SF36) 1 year & 833 & 42.98 & 41.8 & 11.37 & 9 & 48.68 & 45.24 & 12.14 & 0.154 \\
\hline MCS (SF36) 2 years & 723 & 44.94 & 42.68 & 12.21 & 10 & 56.72 & 47.53 & 18.81 & 0.243 \\
\hline PCS (SF36) 1 year & 833 & 52.03 & 47.5 & 12.39 & 9 & 38.71 & 39.75 & 16.33 & 0.537 \\
\hline PCS (SF36) 2 years & 723 & 52.62 & 47.29 & 12.62 & 10 & 38.01 & 40.23 & 13 & 0.396 \\
\hline ODI 1 year & 830 & 20 & 22.65 & 18.28 & 9 & 18 & 21.5 & 20.45 & 0.365 \\
\hline ODI 2 years & 722 & 18 & 22.07 & 19.09 & 10 & 3 & 21 & 31.28 & 0.404 \\
\hline
\end{tabular}

VAS: Visual Analog Scale for pain; EQ5D: European Quality of Life 5 Dimensions; SF36: Short Form Health Questionnaire; MCS: Mental Score Index; PCS: Physiological Score Index; ODI: Oswestry Disability Index; N: Number of Patients; SD: Standard Deviation

Table 5 Subgroup 2 analyzed against the control group.

\begin{tabular}{|c|c|c|c|c|c|c|c|c|c|}
\hline \multirow{2}{*}{ Parameter } & \multicolumn{4}{|c|}{ Control group } & \multicolumn{4}{|c|}{ Subgroup 2} & \multirow{2}{*}{$P$ value } \\
\hline & $N$ & Median & Mean & SD & $N$ & Median & Mean & SD & \\
\hline VAS back pain 1 year & 830 & 18.00 & 27.79 & 26.37 & 37 & 25.00 & 31.16 & 26.89 & 0.773 \\
\hline VAS back pain 2 years & 718 & 17.00 & 27.59 & 27.86 & 35 & 37.00 & 37.55 & 28.95 & 0.053 \\
\hline EQ5D 1 year & 831 & 0.76 & 0.67 & 0.30 & 37 & 0.73 & 0.65 & 0.27 & 0.395 \\
\hline EQ5D 2 years & 723 & 0.80 & 0.68 & 0.32 & 36 & 0.73 & 0.59 & 0.33 & 0.047 \\
\hline MCS (SF36) 1 year & 833 & 42.98 & 41.80 & 11.37 & 37 & 35.18 & 40.12 & 10.52 & 0.412 \\
\hline MCS (SF36) 2 years & 723 & 44.94 & 42.68 & 12.21 & 36 & 34.55 & 38.68 & 12.40 & 0.029 \\
\hline PCS (SF36) 1 year & 833 & 52.03 & 47.50 & 12.39 & 37 & 46.09 & 43.55 & 10.98 & 0.078 \\
\hline PCS (SF36) 2 years & 723 & 52.62 & 47.29 & 12.62 & 36 & 49.32 & 43.65 & 13.32 & 0.037 \\
\hline ODI 1 year & 830 & 20.00 & 22.65 & 18.28 & 37 & 24.00 & 27.48 & 17.32 & 0.163 \\
\hline ODI 2 years & 722 & 18.00 & 22.07 & 19.09 & 35 & 26.00 & 28.39 & 18.82 & 0.053 \\
\hline
\end{tabular}

VAS: Visual Analog Scale for pain; EQ5D: European Quality of Life 5 Dimensions; SF36: Short Form Health Questionnaire; MCS: Mental Score Index; PCS: Physiological Score Index; ODI: Oswestry Disability Index; N: Number of Patients; SD: Standard Deviation

Table 6 Subgroup 3 analyzed against the control group.

\begin{tabular}{|c|c|c|c|c|c|c|c|c|c|}
\hline \multirow{2}{*}{ Parameter } & \multicolumn{4}{|c|}{ Control group } & \multicolumn{4}{|c|}{ Subgroup 3} & \multirow{2}{*}{$P$ value } \\
\hline & $N$ & Median & Mean & SD & $N$ & Median & Mean & SD & \\
\hline VAS back pain 1 year & 830 & 18.00 & 27.79 & 26.37 & 18 & 51.50 & 42.81 & 28.22 & 0.025 \\
\hline VAS back pain 2 years & 718 & 17.00 & 27.59 & 27.86 & 20 & 58.00 & 49.31 & 34.27 & $<0.001$ \\
\hline EQ5D 1 year & 831 & 0.76 & 0.67 & 0.30 & 20 & 0.67 & 0.50 & 0.34 & 0.002 \\
\hline EQ5D 2 years & 723 & 0.80 & 0.68 & 0.32 & 21 & 0.57 & 0.45 & 0.33 & $<0.001$ \\
\hline MCS (SF36) 1 year & 833 & 42.98 & 41.80 & 11.37 & 20 & 32.97 & 35.90 & 12.35 & 0.021 \\
\hline MCS (SF36) 2 years & 723 & 44.94 & 42.68 & 12.21 & 21 & 32.75 & 36.36 & 12.14 & 0.002 \\
\hline PCS (SF36) 1 year & 833 & 52.03 & 47.50 & 12.39 & 20 & 45.40 & 43.82 & 13.12 & 0.084 \\
\hline PCS (SF36) 2 years & 723 & 52.62 & 47.29 & 12.62 & 21 & 43.20 & 41.41 & 14.33 & 0.004 \\
\hline ODI 1 year & 830 & 20.00 & 22.65 & 18.28 & 20 & 36.00 & 35.00 & 18.01 & 0.001 \\
\hline ODI 2 years & 722 & 18.00 & 22.07 & 19.09 & 21 & 35.00 & 34.13 & 18.53 & $<0.001$ \\
\hline
\end{tabular}

VAS: Visual Analog Scale for pain; EQ5D: European Quality of Life 5 Dimensions; SF36: Short Form Health Questionnaire; MCS: Mental Score Index; PCS: Physiological Score Index; ODI: Oswestry Disability Index; N: Number of Patients; SD: Standard Deviation

changes in treatment plans "result in better or worse outcomes for patients." The editor also points out that "this information is vital to justify the use of discography." The value of provocative discography to improve outcome after surgical treatment for CLBP due to DDD is difficult to study and thus unclear. Discography is considered by some to add crucial information before surgery, but a randomized controlled trial would be highly debatable based on ethical considerations. If discography adds information about the most uncertain cases, how could we randomize some patients not to have this before the surgical decision? Could we randomize patients for discography when uncertainty is not an issue, considering the risks of the examination? The 
Table 7 Subgroup 4 analyzed against the control group.

\begin{tabular}{|c|c|c|c|c|c|c|c|c|c|}
\hline \multirow{2}{*}{ Parameter } & \multicolumn{4}{|c|}{ Control group } & \multicolumn{4}{|c|}{ Subgroup 4} & \multirow{2}{*}{$P$ value } \\
\hline & $N$ & Median & Mean & SD & $N$ & Median & Mean & SD & \\
\hline VAS back pain 1 year & 830 & 18.00 & 27.79 & 26.37 & 19 & 31.50 & 36.61 & 29.66 & 0.300 \\
\hline VAS back pain 2 years & 718 & 17.00 & 27.59 & 27.86 & 19 & 21.50 & 29.72 & 31.64 & 0.520 \\
\hline EQ5D 1 year & 831 & 0.76 & 0.67 & 0.30 & 19 & 0.73 & 0.55 & 0.35 & 0.330 \\
\hline EQ5D 2 years & 723 & 0.80 & 0.68 & 0.32 & 19 & 0.78 & 0.58 & 0.37 & 0.200 \\
\hline MCS (SF36) 1 year & 833 & 42.98 & 41.80 & 11.37 & 19 & 39.90 & 40.44 & 11.60 & 0.580 \\
\hline MCS (SF36) 2 years & 723 & 44.94 & 42.68 & 12.21 & 19 & 45.35 & 42.47 & 10.44 & 0.480 \\
\hline PCS (SF36) 1 year & 833 & 52.03 & 47.50 & 12.39 & 19 & 47.55 & 43.36 & 14.60 & 0.400 \\
\hline PCS (SF36) 2 years & 723 & 52.62 & 47.29 & 12.62 & 19 & 53.05 & 47.57 & 15.85 & 0.960 \\
\hline ODI 1 year & 830 & 20.00 & 22.65 & 18.28 & 19 & 27.00 & 27.22 & 20.89 & 0.610 \\
\hline ODI 2 years & 722 & 18.00 & 22.07 & 19.09 & 19 & 18.00 & 22.89 & 18.09 & 0.480 \\
\hline
\end{tabular}

VAS: Visual Analog Scale for pain; EQ5D: European Quality of Life 5 Dimensions; SF36: Short Form Health Questionnaire; MCS: Mental Score Index; PCS: Physiological Score Index; ODI: Oswestry Disability Index; N: Number of Patients; SD: Standard Deviation

present study is aimed at increasing our knowledge on this, but without encountering the ethical problems. The first part of this study [19] analyzed how surgical decisions changed after the information from provocative discography was added. That part of the study concluded that discography changed the prediscography decision in $71 \%$ of cases where uncertainty after the standard investigations prevailed. There has been interest in how the outcome was for this selected study group compared with less complicated patients.

The study group as a whole presents, as expected, a worse outcome than the control group [20, 25], supporting the assumption that the study group was indeed composed of more complicated cases.

When the material was divided into four subgroups, according to the reason and degree of uncertainty, it was obvious that two subgroups had an inferior outcome, even with the information from discography, compared with the control group, whereas two subgroups reached an outcome that was not possible to separate statistically from the control group. This can be interpreted as an indirect indication that, for some patients, provocative discography might, after the change in treatment plan [19], lead to an odds ratio for success more comparable with that for uncomplicated patients. For subgroup 1 with least uncertainty, for which surgery was decided but discography was performed to establish whether the adjacent segment was to be included in the surgical procedure, a segment was added for 10 (55.6\%) patients, none of the patients had a segment removed, and for one patient a re-decision was made not to perform surgery. This subgroup had frequent segment changes (76.9\%) and segment uncertainty was the reason for the discography. One might argue that by eliminating one patient from surgery and having this high frequency of segment changes, a normal odds ratio of beneficial outcome after surgery was more likely for this subgroup.

For subgroups 2 and 3 representing medium uncertainty, the outcome was significantly inferior to that of the control group, even after frequent alterations in surgical plans, either on which segments to treat or whether to operate or not. In subgroup 3, the segment was changed for all patients and it stands out from the other subgroups by having overall worse outcomes compared with the other subgroups and the control group. Subgroup 4, considered beforehand to be the most uncertain, had an outcome after surgery that to our surprise was not statistically different to the control group. In this subgroup, 16 patients had segment changes $(61.5 \%)$, but the highest number of treatment changes. Sixteen patients were changed from no surgery to surgery and one patient was changed from surgery to no surgery. This study has obvious weaknesses. First, the patient groups are not similar, even when treated under the same diagnosis and with the same surgical procedures. Second, what may appear uncertain for one attending surgeon may not appear uncertain for another? In this study, uncertainty of a magnitude that prevented the attending surgeon from finalizing preoperative planning without added information was the threshold for inclusion in the study group. This definition might differ between time points, surgeons, clinics, and countries. Some similarity in the evaluation of these patients is to be expected however. Also, the interpretation of the results of the discography examination, both by the radiologist and the clinician, can be a source of error.

One also must bear in mind the differences in size between the study group with its subgroups and the control group, although the statistical model takes into account and compensates for this relationship. Considering the ethical difficulties described, this was the best design we could find. Several articles on discography have been published and both false-positive and false-negative results have been reported after provocative discography [913]. This study does not add anything to the discussion on falsepositive and false-negative results from discography. It also does not provide any information on other possible effects, psychological or other effects that might have occurred in the patients by just having been referred to and examined by discography.

Among the strengths of this study is that all patients from the previous study who had a Swedish social security number and underwent surgery after discography, were followed. In addition, all discographies were performed in the same manner and by the same radiologist. All patients, both in the study group and the comparative group, were treated under the same diagnosis, during the same time period, and at the same clinic, but by different surgeons. The method of studying patient outcome with 
the outcome scores used in this study is the prevailing method in contemporary literature.

Development of another investigational method to identify patients who would not gain from surgery and tests to clarify what segments to treat is highly warranted.

\section{Conclusion}

Our hypothesis when this part of the study began was that the more complicated patients with more uncertain diagnosis would have an inferior outcome to the control group even after discography, but that the extra examination could bring them to a level of outcome that justified the surgical intervention. From our results, this seems true for two of the four subgroups where outcome was not statistically different from the control group. We therefore conclude that it sometimes might in difficult situations be justified to use provocative discography for patients representing these two uncertain subgroups. The results do absolutely not however, justify the use of this method on a routine basis prior to treatment of DDD, considering the uncertainty and risks of the examination. 


\section{References}

1 Report from the Swedish Council on Technology Assessment in Health Care (SBU) (1991) Back pain-causes, diagnosis, treatment. Int J Technol Assess Health Care 7: 644-646.

2 Reports from the Swedish Council on Technology Assessment in Health Care (2000) Back pain. Int J Technol Assess Health Care16: 929-943.

3 Ekman M, Jonhagen S, Hunsche E, Jonsson L (2005) Burden of illness of chronic low back pain in Sweden: a cross-sectional, retrospective study in primary care setting. Spine 30: 1777-1785.

4 Crock HV (1970) A reappraisal of intervertebral disc lesions. Med J Aust 1: 983-989.

5 van Tulder MW, Koes B, Malmivaara A (2006) Outcome of noninvasive treatment modalities on back pain: an evidence-based review. Eur Spine J 15: S64-S81.

6 Gibson JN, Waddell G (2005) Surgery for degenerative lumbar spondylosis. Cochrane Database Syst Rev CD001352.

7 Chou R, Loeser JD, Owens DK, Rosenquist RW, Atlas SJ, et al. (2009) Interventional therapies, surgery and interdisciplinary rehabilitation for low back pain: an evidence-based clinical practice guideline from the American Pain Society. Spine 34: 1066-1077.

8 Don AS, Carragee E (2008) A brief overview of evidence-informed management of chronic low back pain with surgery. Spine J 8: 258265.

9 Carragee EJ, Lincoln T, Parmar VS, Alamin T (2006) A gold standard evaluation of "discogenic pain" diagnosis as determined by provocative discography. Spine 31: 2115-2123.

10 Wolfer LR, Derby R, Lee JE, Lee SH (2008) Systematic review of lumbar provocation discography in asymptomatic subjects with a meta-analysis of false-positive rates. Pain Physician 11: 513-538.

11 Manchikanti L, Boswell MV, Singh V, Derby R, Fellows B, et al. (2009) Comprehensive review of neurophysiologic basis and diagnostic interventions in managing chronic spinal pain. Pain Physician 12: E123-E198.

12 Manchikanti L, Glaser SE, Wolfer L, Derby R, Cohen SP (2009) Systematic review of lumbar discography as a diagnostic test for chronic low back pain. Pain Physician 12: 541-559.

13 Alamin TF, Kim MJ, Agarwal V (2011) Provocative lumbar discography versus functional anesthetic discography: A comparison of the results of two different diagnostic techniques in 52 patients with chronic low back pain. Spine J 11: 756-765.

14 Manchikanti L, Boswell MV, Singh V, Benyamin RM, Fellows B, et al. (2009) Comprehensive evidence-based guidelines for interventional techniques in the management of chronic spinal pain. Pain Physician12: 699-802.

15 Carragee EJ, Don AS, Hurwitz EL, Cuellar JM, Carrino JA, et al. (2009) ISSLS Prize Winner: Does discography cause accelerated progression of degeneration changes in the lumbar disc: a ten-year matched cohort study. Spine 34: 2338-2345.

16 Hebelka H, Nilsson A, Hansson $\mathrm{T}$ (2014) Pressure increase in adjacent discs during clinical discography questions the methods validity. Spine 39: 893-899.

17 European Commission (2001) Radiation protection 118 referral guidelines for imaging. Luxembourg: Office for Official Publications of the European Communities.

18 Fryback DG, Thornbury JR (1991) The efficacy of diagnostic imaging. Med Decis Making 11: 88-94.

19 Berg S, Isberg B, Josephson A, Fallman M (2012) The impact of discography on the surgical decision in patients with chronic low back pain. Spine J 12: 283-291.

20 Strömqvist B, Fritzell P, Hägg O, Jonsson B, Sanden B, et al. (2013) SweSpine: The Swedish spine register: The 2012 report. Eur Spine J 22: 953-274.

21 Sköld C, Tropp H, Berg S (2013) Five-year follow-up of total disc replacement compared to fusion: A randomized controlled trial. Eur Spine J 22: 2288-2295.

22 Hägg O, Fritzell P, Odén A, Nordwall A, Swedish Lumbar spine study group (2002) Simplifying outcome measurement. Evaluation of instruments for measuring outcome after fusion surgery for chronic low back pain. Spine 27: 1213-1222.

23 Brooks R (1996) EuroQol: The current state of play. Health Policy 37: $53-72$

24 Fairbank JC, Couper J, Davies JB, O'Brien JP (1980) The Oswestry low back pain disability questionnaire. Physiotherapy 66: 271-273.

25 Ware JE, Sherbourne CD (1992) The MOS 36-item short-form health survey (SF-36). I. Conceptual framework and item selection. Med Care 30: 473-483.

26 Chapman JR, Norvell DC, Hermsmeyer JT, Bransford RJ, Devine J, et al. (2011) Evaluating common outcomes for measuring treatment success for chronic low back pain. Spine 36: S54-S68. 